Available online on 15.05.2020 at http://jddtonline.info
Open Access to Pharmaceutical and Medical Research
unrestricted non-commercial use, provided the original work is properly cited

Open $\odot$ Access

Research Article

\title{
Comparative Study of Chitosan and Carboxy Methyl Chitosan Nanoparticles in Mefenamic Acid Drug Delivery
}

\author{
Parankusham Vedavahini*, Dr. Chintha Sailu \\ University College of technology, Osmania University, Hyderabad, India
}

\begin{abstract}
Nanoparticle based technologies improve the efficiency and speed of already existing processes.The larger size materials and reagents which are in reactive form, can be nanosized to give efficient output. Chitosan and the carboxy methyl chitosan nanoparticles were prepared by using solvent evaporation nanoprecpitation method, loaded with mefenamic acid, (anthranilic acid derivative) a poorly aqueous soluble drug. Mefenamic acid, if used as conventional dosage form, duration of action was 6 hours; when the drug loaded into Chitosan and the carboxy methyl chitosan nanoparticles the drug release profile was up to $26 \mathrm{hrs}$. The particle size, entrapment efficiency, poly dispersity index, drug loading, drug release profiles of mefenamic acid were compared for both nanoparticles and it was observed that carboxy methyl chitosan nanoparticles released mefenamic acid more effectively than chitosan nanoparticles.
\end{abstract}

Keywords: Nanoparticles, Chitosan, Carboxy methyl chitosan, Mefenamic acid

Article Info: Received 12 March 2020; Review Completed 20 April 2020; Accepted 29 April 2020; Available online 15 May 2020

Cite this article as:

Vedavahini P, Sailu C, Comparative Study of Chitosan and Carboxy Methyl Chitosan Nanoparticles in Mefenamic Acid Drug Delivery, Journal of Drug Delivery and Therapeutics. 2020; 10(3):83-96 http://dx.doi.org/10.22270/jddt.v10i3.3980

*Address for Correspondence:

Parankusham Vedavahini, H.No-9-111/77, Street No 4, Anjaneyanagar, Boduppal, Dist.-Medchal., Hyderabad -500092, Telangana, India

\subsection{INTRODUCTION}

\subsection{Nanoparticles}

International Organization of Standardization (ISO) in 2008, defined nanoparticles as that all the Cartesian dimensions should be less than $100 \mathrm{~nm}$. ISO defined nano discs, nanoplates as two dimensional nano objects; nano fibers and nanotubes as one dimensional nano objects. As per the European Union commission in 2011, definition of nanoparticle is 'a natural, manufactured, incidental material containing particles, in an unbound state or as an agglomerate or as an aggregate and where of $50 \%$ of or more of the particles in the number size distribution one are more external dimensions in the size range of $1 \mathrm{~nm}-100 \mathrm{~nm}$.

\subsection{Nanodrug delivery system}

Preparation of nanoparticles are generally applicable to the drugs which are poorly aqueous soluble, the solubility can be increased by size reduction process, this can be done by various methods like milling, high pressure homogenization, high temperature evaporation, vacuum deposition 1 . These nanonization methods are useful to increase the bioavailability of drug to the target $s^{2}{ }^{2}$. Nanosized molecules can target the drug to the specific site without affecting the normal cell line ${ }^{3}$. Nanoparticles surface is covered with polymers or ligands so that they can identify and conjugate with disease site and release the drug at a constant rate and can cure the disease 4 .

Studies have been done on animal models in vivo and systemic cell culture in vitro reveals the toxicity of nanopaticles includes respiratory system, skin, lungs, brain, and reproductive toxicity ${ }^{5}$. Due to very less size of nanoparticles, possess more free energies, thus causing aggregation and agglomeration at targeted site. If these drugs are insoluble in biological origin (they may reach other than targeted site) may affect internal organs during their exposure ${ }^{6,7}$. Negative effects like new toxins and environment pollutants may be produced by nanotechnology process $^{8}$.

\subsection{Chitosan}

Chitin and chitosan have similar structure. Chitosan is a linear polysaccharide composed of randomly distributed $\beta$ (1-4)-linked D-glucosamine (deacetylated unit) and N-acetylD-glucosamine (acetylated unit). Chitosan is produced commercially by deacetylation of chitin, this process is never complete. Chitin is soluble in glacial acetic acid, hydrochloric acid, nitric acid, perchloric acid, phosphoric and formic acid 
after stirring at certain temperature ${ }^{9,10}$, Insoluble in water and other organic acids and bases. Unlike chitin, chitosan is hydrophilic polymer. In chitosan reactive amino groups protonated in acids with pKa less than 6.2 makes chitosan soluble. Chitosan is biocompatible, immunoadjuvant, nonimmunogenic, nontoxic, inexpensive, water soluble, stable after administration, applicable to a broad category of drugs ${ }^{11 .}$

Over years liposomes are used as drug carriers for targeted drug delivery. But these liposomes have poor reproducibility, stability and low drug entrapment activity. To overcome this problem polymeric nanoparticles have been prepared to get better stability profiles and reproducibility and are taken as alternative drug carriers ${ }^{12}$.

Poor stability is major limiting step in the preparation of chitosan nanoparticles. To maintain stability, temperature, environmental factors can be maintained optimized and with a suitable stabilizer; chitosan structure can be changed with proper ionic or chemical compound 13 . Another limitation of chitosan nanoparticles is the poor solubility ${ }^{14}$. Unmodified chitosan nanoparticles can encapsulate some hydrophilic drugs. Modified chitosan nanoparticles can encapsulate hydrophobic drugs. So poor solubility is major problem for some drugs in preparation of chitosan nanoparticles ${ }^{13}$. In most of the cases, in vitro studies show efficient results but failed to show the same in vivo ${ }^{15}$.
Finally, financial support to the industries as well as to the patients to be taken into consideration, due to expensive protocols to be followed in the preparation of NPs, and cost of nanomedicine in the markets 16 .

\subsection{Carboxy Methyl Chitosan (CMC)}

Carboxy methyl chitosan is derivative of chitosan. Solubility is more when compared with chitosan. Chitosan solubility is very less at $\mathrm{pH}>6$, but for the applications in preparation of pharmaceutical products, solubility plays major role and important factor. Chitosan derivative is prepared to increase the solubility. Chitosan is converted to carboxy methyl chitosan by direct alkylation process as these carboxy methyl moieties will change the properties of chitosan ${ }^{17}$.This type of chemical modification by direct alkylation will add carboxy methyl groups to two- $\mathrm{OH}$ groups (primary\& secondary alchohol) and one amino group ${ }^{18}$.The extent of water solubility depends on degree of substitution with carboxymethylation. As chitosan is converted into Carboxymethyl chitosan, it will change its physical and biological properties like moisture retention, chelating, sorption, cell functioning, antioxidant, antibacterial, anti apoptotic etc ${ }^{19}$. Carboxymethyl chitosan is used in different drug delivery systems like in DNA drug delivery as permeation enhancer, $\mathrm{pH}$ responsive drug delivery. nCarboxymethyl chitosan was first prepared and developed by Muzzarelli in 1982, it was tested, used as ingredient in cosmetic and biomedical field $20,21,22$.

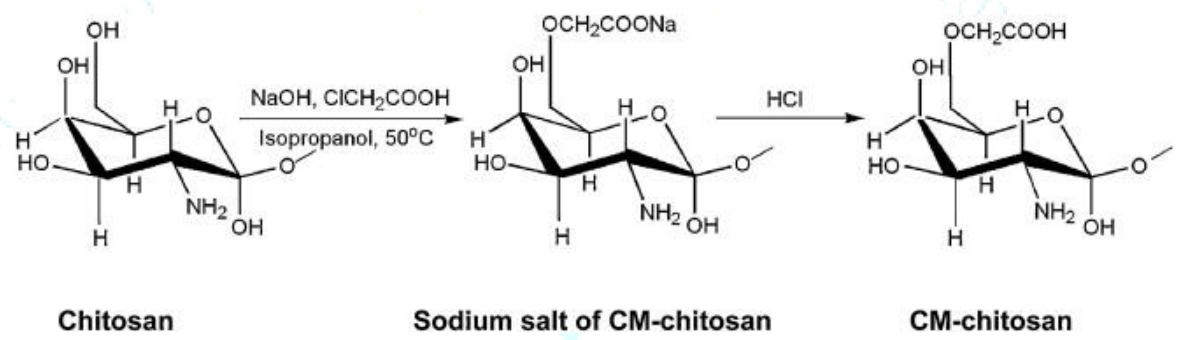

Figure1.1: Synthesis of carboxytmethyl chitosan

\subsection{Mefenamic acid}

Mefenamic acid is non-narcotic, non-steroidal antiinflammatory drug. It is used in the treatment of arthritis, pain, migraine associated with heavy menstruation, pain after surgical operations. It is anthranilic acid derivative.<smiles>Cc1cccc(Nc2ccccc2C(=O)O)c1C</smiles>

Fig. 1.2: Molecular structure of Mefenamic acid

It is Greyish white odour less, microcrystalline powder; Molar mass-241.285; Water solubility-0.004\% at pH-7.1; Formula-C15H15NO2; Chemical Name-N-2,3 xylylanthranilic acid; Melting point $230^{\circ}-231^{\circ} \mathrm{C}$; MetabolismHepatic; Mechanism of action is not clearly known, like other NSAIDs, inhibits COX-1\&COX-2, potent inhibitor of prostaglandin synthesis, analgesic, antipyretic, antiinflammatory.

Dose required is $500 \mathrm{mg}$ followed by $250 \mathrm{mg}$ for every 6 hours, not exceeded for one week.

\subsubsection{Pharmacokinetics of Mefenamic Acid}

Administered orally, distributed in protein bound form, metabolised in liver, metabolites are excreted mainly in the urine. Onset of Action- 1-2 hrs; Duration of Action- 6 hrs; Half Life -2-4 hours.Side Effects are nausea, vomiting, anorexia, diarrhoea, gastrointestinal bleeding, abdominal distress, constipation, peptic ulcer, dyspepsia, headache, flatulence, insomnia, drowsiness, rash, aplastic anaemia, thrombocytopenia, dizziness; Contra-indicated in patients with hypersensitivity, inflammatory bowel disease, peptic ulcer, pregnancy, breast Feeding, below 14 years of age.

Special Precautions- Hepatic \& Renal impairment, Hypertension, Gastrointestinal diseases, Pre-existing asthma, impairment, Myocardial infarction, Heart failure, Patient on anticoagulant therapy, Stroke

Old Age -Use with caution; Neonates- used only to close the patent ductus arteriosus as IV form only

Indications: Muscular aches, Primary Dysmenorrhoea, Headaches, Acute gout, Dental pain, Patent ductus arteriosus ; Storage - Store at room temperature in a tightly closed light resistant container. 


\subsection{MATERIALS AND METHODS}

\subsection{Chemicals}

Standard chitosan was purchased from Chemica and Biochemica. Mefenamic acid and other chemicals (chloroacetic acid, sodium hydroxide), solvents (2-propanol and methanol), reagents, buffers used were of analytical grade; purchased from standard manufacturers.

\subsection{Synthesis of Carboxy Methyl Chitosan (CMC)}

$2 \mathrm{~g}$ of Chitosan suspended in $20 \mathrm{ml}$ of $50 \%$ (w/v) sodium hydroxide was left swelling for 1 hour at room temp and kept for alkalization for $12 \mathrm{~h}$ at $-20^{\circ} \mathrm{C}$, then thawed at room temperature. This alkali chitosan was suspended into $50 \mathrm{ml}$ of 2-propanol solution and the mixture was stirred on magnetic stirrer for 30 min and then in water bath shaker at $50^{\circ} \mathrm{C}$. $10 \mathrm{~g}$ of Chloroacetic acid dissolved in $30 \mathrm{ml}$ of isopropanol was added drop wise over a period of $30 \mathrm{~min}$. Reaction mixture was stirred for 12 hours in a water bath at $50^{\circ} \mathrm{C}$. Then the liquid fraction was decanted and $100 \mathrm{ml}$ of methanol was added to the resulting slurry. The suspension was neutralized using glacial acetic acid. Then the mixture was filtered and washed several times with methanol. The resulting CMC was purified by dissolving in deionized water and filtered to remove undissolved residues. The resultant solution was precipitated in addition of methanol. Finally the pure product was separated by filtration, rinsed with methanol, vacuum freeze dried and stored in desiccators until further use.

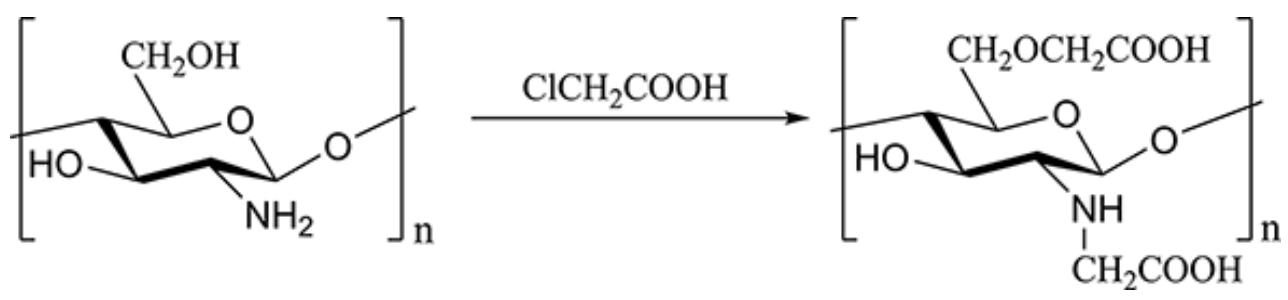

Figure-2.1- N- and 0-carboxymethylation of chitosan

\subsubsection{Characterization of CMC by degree of substitution}

The degree of substitution of CMC was determined by potentiometric titration. CMC was dissolved in distilled water and the solution was adjusted to $\mathrm{pH}<2$ by addition of hydrochloric acid. Then, the CMC solution was titrated with $0.1 \mathrm{M}$ aqueous sodium hydroxide and the $\mathrm{pH}$ value of the solution was simultaneously recorded. The amount of aqueous sodium hydroxide was determined by the second order differential method. The degree of substitution (DS) was calculated as follows:

$$
D S=\frac{(v 2-v 1) D D}{(v 3-v 2)}
$$

$\mathrm{V} 1=\mathrm{NaOH}$ volume at $\mathrm{pH}-3, \mathrm{~V} 2=\mathrm{NaOH}$ volume at $\mathrm{pH}-3.8$, $\mathrm{V} 3=\mathrm{NaOH}$ volume at $\mathrm{pH}-5, \mathrm{DD}$ (degree of deacetylation of chitosan); Where Vsodium hydroxide and Csodium hydroxide are the volume and molarity of aqueous sodium hydroxide, respectively; $\mathrm{mCMC}$ is the mass of CMC (g), and 161 and 58 are the molecular weight of glucosamine (chitosan skeleton unit) and a carboxymethyl group, respectively.

\subsection{Estimation of Mefenamic acid}

UV visible spectroscopic method for analysis of Mefenamic acid was adopted in present work. An accurately weighed quantity of Mefenamic acid (100mg) was dissolved in 100 $\mathrm{mL}$ of 7.4 buffers to generate a stock solution having concentration of $10^{3} \mu \mathrm{g} / \mathrm{mL}$. Stock solution $(10 \mathrm{~mL})$ was further diluted to $100 \mathrm{~mL}$ to produce standard solution having concentration of $10^{2} \mu \mathrm{g} / \mathrm{mL}$. The standard solution was serially diluted with 7.4 buffer to get working standard solutions having concentration of $2,4,6,8,10 \mu \mathrm{g} / \mathrm{mL}$. The absorbance of the solutions was measured at $285.0 \mathrm{~nm}$ using double beam UV visible spectrophotometer against 7.4 buffer as a blank.

\subsection{Drug Excipient Compatibility Study}

Drug and excipients were mixed and placed at room temperature for 24 hours. The presence of any drugpolymer interaction was studied by FT-IR spectroscopy.

\section{Fourier-transform infrared spectroscopy}

To examine possible chemical interactions of MFA-CS NPs and interactions of MFA-CMC NPs, Fourier-Transform Infrared Spectroscopy (FT-IR) was used. The IR spectra of Chitosan, CMC, MFA, MFA-CN NPs, MFA-CMC NPs were recorded using an FT-IR spectrophotometer (FT-IR Nicolet380, Thermo Fisher Scientific, Madison, USA). Samples were mixed with potassium bromide (spectroscopic grade) and compressed into disks using a hydraulic press before scanning from 4000 to $600 \mathrm{~cm}^{-1}$. Data were analyzed using FT-IR solution software (version 1.10).

2.5 Formulation of MFA-chitosan nanoparticles (MFACSNPs) and MFA-CMC nanoparticles(MFA-CMC NPs)

MFA-CSNPs and MFA-CMC NPs were prepared by solvent evaporation and nano-precipitation techniques. The influence of different independent variables as Chitosan concentration (\%), tween 80 concentration (\%) and sonication time $(\mathrm{min})$ were evaluated on particle size $(\mathrm{nm})$, drug loading (\%) and in vitro drug release (\%) were investigated.

Chitosan, CMC containing mefenamic acid-NPs were prepared using combined technique of solvent evaporation and nanoprecipitation technique with slight modification ${ }^{23}$. This was a two-step process, in the first step; emulsification of the polymer solution into aqueous phase containing a surfactant was done. Then in the second step evaporation of polymeric solvent was carried out, inducing polymer precipitation of the nanoparticles ${ }^{24}$. The calculated quantities of chitosan/Carboxy methyl chitosan and tween 80 and PVA were varied according to the experimental design. For the preparation of MFA-CNPs concentrations of chitosan $(2 \%, 3.5 \%, 5 \%)$, tween $80(2 \%, 4.5 \%, 7 \%)$, sonication time (3min,5min,7min) were used as low, medium, high levels of independent variables. For the preparation of MFACMC nanoparticles concentrations of chitosan $(2 \%, 4 \%, 6 \%)$ tween $80(3 \%, 5 \%, 7 \%)$, sonication time $(2 \mathrm{~min}, 5 \mathrm{~min}, 7 \mathrm{~min})$ were used as low, medium, high levels of independent variables. Chitosan was dissolved in an organic solvent acetone $(10 \mathrm{~mL})$ and separately tween 80 dissolved in 
double distilled water. The organic solvent was added slowly to the aqueous phase containing tween 80 with a constant stirring on magnetic stirrer at room temperature. The evaporation of the organic solvent was performed at a temperature range of $65-80^{\circ} \mathrm{C}$ which involves precipitation process lead to formation of nanoparticles. The obtained nanoparticles were ultra sonicated for different time interval (3-7 min.) at $60-80 \mathrm{KHz}$ amplitude) for 1 cycle and allowed to cool at room temperature. The developed MFA-CSNPs and MFA-CMC NPs were lyophilized using the freeze dryer at a chamber pressure (20pa) and cold trap temperature ($120^{\circ} \mathrm{C}$ ) in the entire process. The study was performed for $24 \mathrm{~h}$ for freezing, $4 \mathrm{~h}$ for primary drying at $0^{\circ} \mathrm{C}$, followed by $10^{\circ} \mathrm{C}$ for $2 \mathrm{~h}$ and $15^{\circ} \mathrm{C}$ for $1.5 \mathrm{~h}$ and secondary drying at $25^{\circ} \mathrm{C}$ for $3 \mathrm{~h}$. Mannitol (3\%) was added as a cryoprotectant to avoid lysis of nanoparticles ${ }^{25}$.

\subsection{Evaluation of Nanoparticles}

\subsubsection{Particle size and size distribution}

The average particle size and size distribution(PDI) of mefenamic acid loaded nanoparticles of Chitosan and CMC were determined by dynamic laser scattering (DLS) technology using a Zeta sizer Nano ZS(Malvern instruments, Malvern, UK). The nano suspensions were suitably diluted with ultrapure water and sonicated for $2 \mathrm{~min}$ to form a uniform dispersion before placing the sample in quartz cuvette. The hydrodynamic diameter of particles was measured with a He-Ne laser at a scattering angle of $90^{\circ}$ at $25^{\circ} \mathrm{C}$. Each sample was determined three times and the obtained results were expressed as the mean size of particle \pm SD.

\subsubsection{Measurement of surface charge}

The zeta potential of the nanoparticles was determined by an electrophoretic light scattering technique using a Zetasizer Nano ZS (Malvern Instruments Ltd., UK). A diluted sample of nanoparticles in water was allowed to stabilize at $25^{\circ} \mathrm{C}$ and was placed in the clear disposable zeta cells. Zeta potential was obtained based on the electrophoretic mobility between the electrodes. The experiments were performed in triplicate and the results were expressed in millivolts $(\mathrm{mV})$

\subsubsection{Surface morphology}

The surface morphology of the nanoparticles was observed by scanning electron microscopy. Sample preparation was done by placing a drop of the nanosuspension on an aluminium stub. The particles were allowed to settle and the excess of the liquid in suspension sample was removed with a capillary. The sample was then coated with $30 \mathrm{~nm}$ layer of gold using JEOL JFC 1100E sputter coater for 30s and viewed under SEM (JSM 840A, JOEL, Japan).

\subsubsection{Entrapment Efficiency\& Drug loading}

Entrapment efficiency (EE\%) and drug loading (DL\%) of the developed MFA-CSNPs and MFA-CMC

NPs were determined by double beam UV Spectroscopy. The prepared nanoparticles were subjected to centrifugation at a speed of 10,000 rpm (Remi centrifuge, Mumbai, India) for $20 \mathrm{~min}$ and the free drug content in the supernatant was separated and the separated NPs were solubilised in appropriate medium(methanol) and filtered through a 0.22 $\mu \mathrm{m}$ PVDF filter/ultra filter (Pall Life Sciences, Mumbai, India). The supernatant was collected and diluted with an appropriate solvent (methanol) to analyze using UVspectrophotometer at $285 \mathrm{~nm}$. Consequently, the EE\% and DL\% were calculated by the following formula:

$$
\mathrm{EE} \%=\frac{\text { Total amount of drug }- \text { amount of free drug }}{\text { Total amount of drug }} \times 100
$$

Drug loading $=\frac{\text { Total amount of drug }- \text { amount of free drug }}{\text { Total weight of the nanoparticle }} \times 100$

\subsubsection{Drug release Profile}

The drug release study of chitosan and CMC nanoparticles was performed separately with activated dialysis bag technique (molecular weight $12000 \mathrm{~g} / \mathrm{mol}$, Sigma, MO, USA) with slight modification from suggested methods. A known volume containing nanoparticles in both the formulation was placed in a dialysis bag, and both ends were tied to prevent any leakage. The bag was dipped in $250 \mathrm{ml}$ phosphate buffer saline ( $\mathrm{pH} 7.4)$ as release media at $37 \pm 2$ ${ }^{\circ} \mathrm{C}$ with continuous stirring at $50 \mathrm{rpm}^{25}$. The release samples $(1 \mathrm{ml})$ were withdrawn at predetermined time interval and were filtered through $0.22 \mu \mathrm{m}$ PVDF Syringe filter. The amount of drug release was calculated by using UVspectrophotometer at $285 \mathrm{~nm}$ using buffer (pH 7.4) a blank sample.

\subsection{RESULTS}

\subsection{Results of synthesis and characterization of CMC}

CMC was characterized by potentiometric titration. By this titration one can conclude that the percentage of carboxy methyl groups added to the chitosan.Figure-3.1- The potentiometric titration curves of four Carboxy methyl chitosan solutions. Since protonated chitosan was not considered in the study, there is no point after $\mathrm{pH}$ 7.0. It was clearly shown that the range of titration jumps were around $\mathrm{pH} 3.0-5.0$ and the inflection point's are located at $\mathrm{pH} 3.80$, thus this point was used as the titration end-point in the solution. The titration end-point $\mathrm{pH} 3.80$ cannot be applied to all CMC samples because of the different origins of samples. In addition, the $\mathrm{pH}$ value responded from the composite glass electrode lags behind the $\mathrm{pH}$ true value and reagent blank error can affect the result of analysis ${ }^{26,27}$.

$$
\mathrm{DS}=\frac{(\mathrm{V} 2-\mathrm{V} 1) \times \mathrm{DD}}{\mathrm{V} 3-\mathrm{V} 2}
$$

$\mathrm{V} 1=\mathrm{NaOH}$ volume at $\mathrm{pH}-3=5, \mathrm{~V} 2=\mathrm{NaOH}$ volume at $\mathrm{pH}-$ $3.8=5.8, \mathrm{~V} 3=\mathrm{NaOH}$ volume at $\mathrm{pH}-5=6.8$, DD (degree of deacetylation of chitosan) $=0.64$



Figure-3.1- Degree of Substitution of Carboxy methyl chitosan

\subsection{Results of Estimation of Mefenamic acid}

UV visible spectroscopic method for analysis of Mefenamic acid was adopted in present work. An accurately weighed quantity of Mefenamic acid (100mg) was dissolved in 100 $\mathrm{mL}$ of 7.4 buffer to generate a stock solution having concentration of $10^{3} \mu \mathrm{g} / \mathrm{mL}$. Stock solution $(10 \mathrm{~mL})$ was further diluted to $100 \mathrm{~mL}$ to produce standard solution having concentration of $10^{2} \mu \mathrm{g} / \mathrm{mL}$. The standard solution 
was serially diluted with 7.4 buffer to get working standard solutions having concentration of $2,4,6,8,10 \mu \mathrm{g} / \mathrm{mL}$. The absorbance of the solutions was measured at $285.0 \mathrm{~nm}$ using double beam UV visible spectrophotometer (Figure-3.2) against 7.4 buffer as a blank. The plot of absorbance $\mathrm{v} / \mathrm{s}$ concentration $(\mu \mathrm{g} / \mathrm{mL})$ was plotted (Figure 3.3) and data was subjected to linear regression analysis in Microsoft excel.

3.3.1 Preparation of standard calibration curve of Mefenamic acid in 7.4 buffer at $285 \mathrm{~nm}$

Calibration curve of Mefenamic acid was developed in $0.1 \mathrm{~N}$ $\mathrm{HCI}$ at $285.0 \mathrm{~nm}$ wave length. Mefenamic acid in 7.4 buffer showed good linearity $\left(r^{2}=0.990\right)$ and intercept 0.010 over the concentration range of $2-10 \mu \mathrm{g} / \mathrm{ml}$ at $\lambda \max 285 \mathrm{~nm}$. The data for calibration curve are shown in Table 3.3 and the calibration curve was shown in Figure 3.3 .

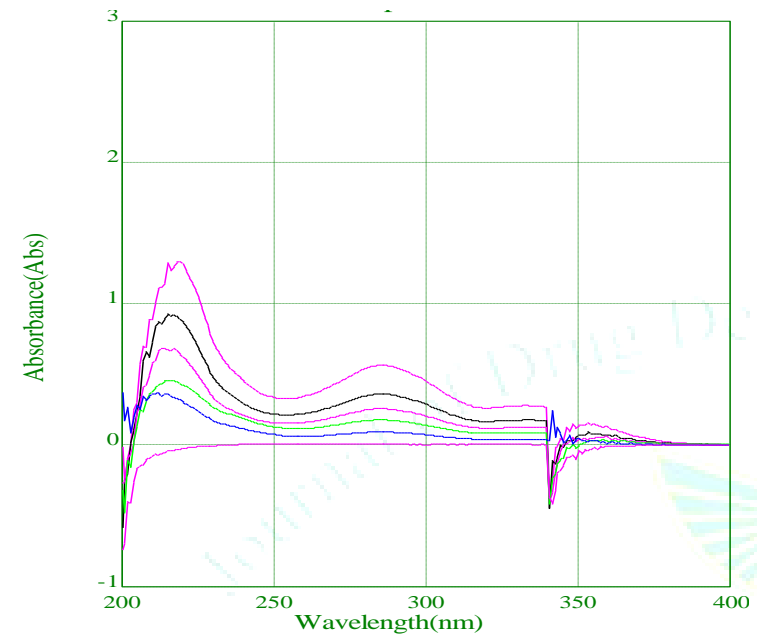

Figure 3.2 Spectra of Mefenamic Acid By UVSpectroscopy

Table 3.1 Standard curve of Mefenamic Acid in 7.4 Buffer at $285 \mathrm{~nm}$

\begin{tabular}{|l|c|c|}
\hline S.No. & Concentration $(\boldsymbol{\mu g} / \mathbf{m l})$ & Absorbance \\
\hline $\mathbf{1}$ & 2 & 0.1177 \\
\hline $\mathbf{2}$ & 4 & 0.1764 \\
\hline $\mathbf{3}$ & 6 & 0.2688 \\
\hline $\mathbf{4}$ & 8 & 0.3684 \\
\hline $\mathbf{5}$ & 10 & 0.4717 \\
\hline
\end{tabular}

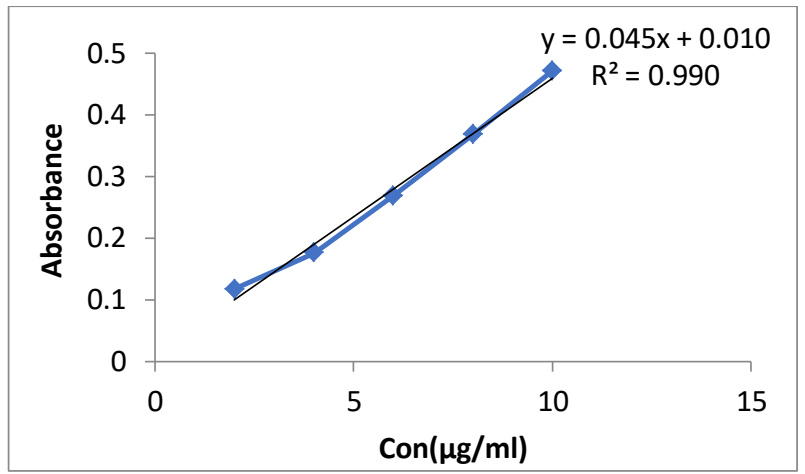

Figure 3.3-Standard curve of Mefenamic Acid in 7.4 Buffer at $285 \mathrm{~nm}$

3.4 Results of evaluation of mefenamic acid loaded chitosan nanoparticles

3.4.1 FTIR Results of Mefenamic acid, Chitosan, MFACSNP

FT-IR spectroscopy was used to analyze the possible interactions between the drug and polymers used to form MFA loaded CSNPs. The FTIR spectra of MFA, Chitosan and CSNPs formulations were represented in Figure-3.4 There are primarily determinant peaks of Chitosan around 3433 cm-1 (-OH and $\mathrm{eNH}_{2}$ stretching), $2876 \mathrm{~cm}-1 \quad(-\mathrm{CH}$ stretching), $1594 \mathrm{~cm}-1$ (-NH2 stretching), $1396 \mathrm{~cm}-1$ (-CN stretching), $1018 \mathrm{~cm}-1$ (CeOeC stretching), and $615 \mathrm{~cm}-1$ (pyranoside ring stretching vibration). In addition, in preparation of CSNPs, the peak of $3433 \mathrm{~cm}-1$ becomes wider, representing that hydrogen binding has been introduced in Chitosan in nanostructure. The peak of $1594 \mathrm{~cm}-1$ for $\mathrm{eNH}_{2}$ shifted to around $1572 \mathrm{~cm}-1$ and a new sharp peak at 1700 cm-1appeared, which can be explained by the interaction of $\mathrm{NH}_{2}$ of Chitosan. Compared with the spectrum of MFA, in the spectrum of MFA/CSNPs, the absorption peak of about 1632 cm-1 (carboxyl group) shifted and a new shoulder peak of $1572 \mathrm{~cm}^{-1}$ (carboxyl salt) appears. It seems that hydrogen bonds formed between $\mathrm{OH}$ groups of the MFA and those of Chitosan and electrostatic interaction taken place between COO- of the drug and $\mathrm{NH}_{3} \mathrm{p}$ of chitosan. Moreover, the increase in MFA concentration leads to appearance of MFA characteristic absorption peaks at high intensities. On the other hand, using a low MFA weight ratio in the NP (F1) caused the appearance of these characteristic peaks, but at low intensity. The results of FTIR are in agreement with previous studies.

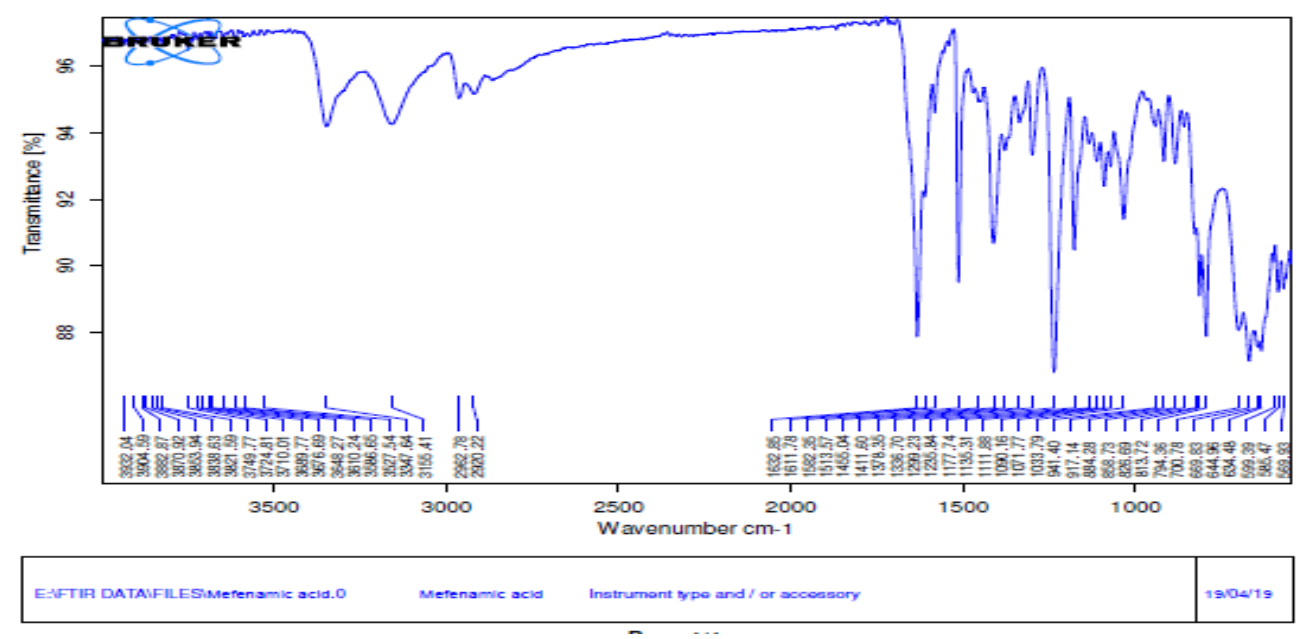

Figure-3.4.1- FTIR of Mefenamic acid 


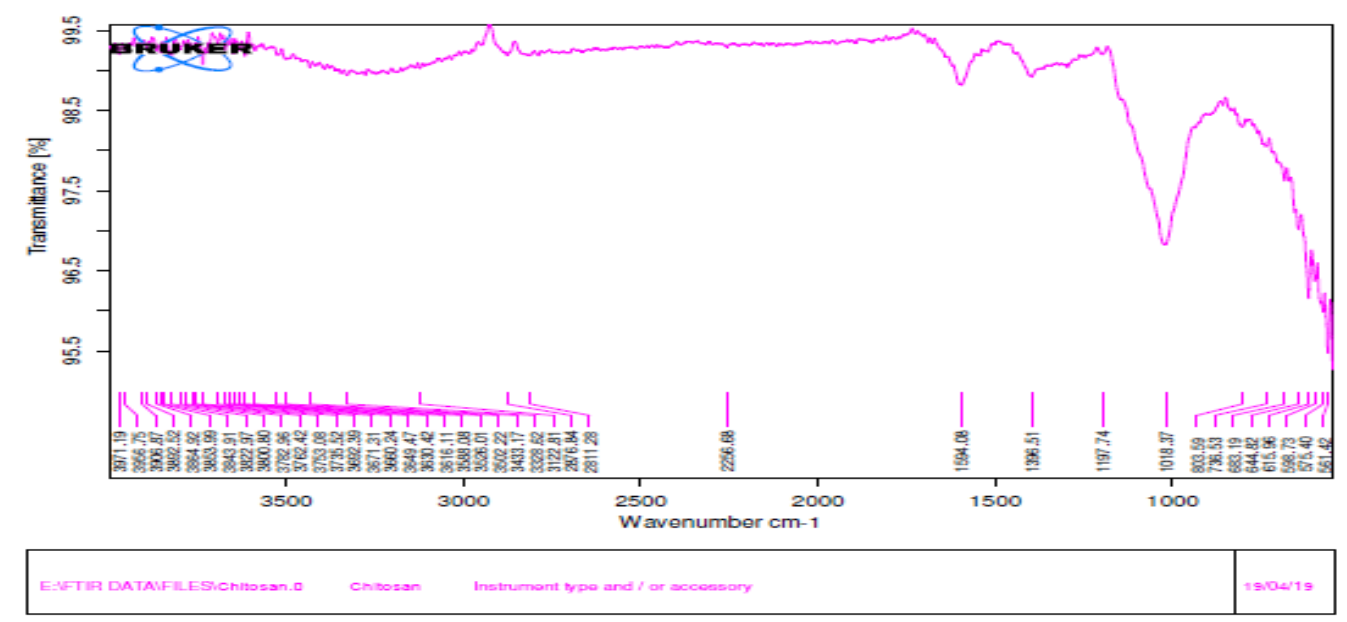

Figure-3.4.2- FTIR of Chitosan

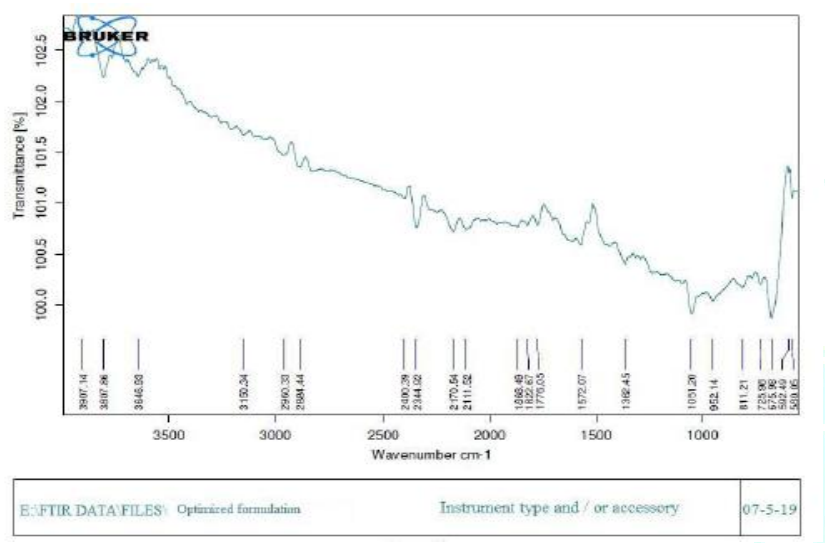

Figure-3.4.3 - FTIR of optimized formulation of MFACSNP

3.4.2 Effect of concentration and sonication time of chitosan on particle size, PDI, EE\% and DL\% of formulations of MFA loaded chitosan nanoparticles

The above results depicted the average size of different chitosan loaded nanoparticles and the corresponding polydispersity index (PDI) was shown in Table 3.2. The size of ranged from 150 to $245 \mathrm{~nm}$; Based on the EPR(enhanced permeability and retention) effect, the nanoparticles under $200 \mathrm{~nm}$ were the most suitable for penetrating the blood vessels into tumor tissue. All of the three Chitosan based nanoparticles under certain preparing conditions could meet this requirement with favourable PDI. For the nanoparticle stability the zeta potential should be between $-25 \mathrm{mV}$ to $+25 \mathrm{mV}$. Zeta potential of chitosan MFA nanoparticle is found to be $-1.8 \mathrm{mV}$ (Figure-3.6). The cumulative particle size is 1241.5 (Figure-3.5).

The results in Table 3.2, showed the interaction effect of chitosan concentration and Sonication time on the EE\% and DL\% of MFA loaded CSNPs. These result revealed that EE\% varies from $44.58 \pm 3.30 \%$ to $82.65 \pm 1.16$, F1 having high chitosan concentration and longest sonication time showed 82.65\% Entrapment Efficiency due to cross linking of chitosan with drug. DL\% varied from $3.93 \%$ to $8.14 \%$ This could be attributed to the binding of hydroxyl groups of MFA to positively charged amino groups on chitosan molecules by electrostatic interaction These results might be attributed to an increase number of interacting units at higher polymer concentrations and to cross-linker levels that lead to the observed increase in particle size and decrease entrapment efficiency

Table 3.2-Particle size of MFA loaded chitosan nanoparticles

\begin{tabular}{|l|l|l|l|l|l|l|}
\hline Formulation & Chitosan & $\begin{array}{l}\text { Sonication } \\
\text { time }\end{array}$ & $\begin{array}{l}\text { Particle } \\
\text { size(nm) }\end{array}$ & PDI & EE\% & DL\% \\
\hline F1 & +1 & +1 & $150 \pm 7.9$ & $0.23 \pm 0.02$ & $82.65 \pm 1.16$ & $8.14 \pm 0.07$ \\
\hline F2 & 0 & +1 & $210 \pm 9.1$ & $0.22 \pm 0.03$ & $72.48 \pm 0.45$ & $7.29 \pm 0.03$ \\
\hline F3 & -1 & +1 & $225 \pm 8.1$ & $0.33 \pm 0.02$ & $58.41 \pm 0.85$ & $5.86 \pm 0.08$ \\
\hline F4 & +1 & 0 & $187 \pm 8.9$ & $0.24 \pm 0.01$ & $72.10 \pm 1.21$ & $7.24 \pm 0.20$ \\
\hline F5 & 0 & 0 & $245 \pm 10.1$ & $0.21 \pm 0.04$ & $67.50 \pm 0.82$ & $6.83 \pm 0.03$ \\
\hline F6 & -1 & 0 & $170 \pm 6.9$ & $0.22 \pm 0.04$ & $77.12 \pm 0.49$ & $7.74 \pm 0.04$ \\
\hline F7 & +1 & -1 & $175 \pm 7.9$ & $0.24 \pm 0.03$ & $63.19 \pm 0.83$ & $5.93 \pm 1.06$ \\
\hline F8 & 0 & -1 & $164 \pm 9.9$ & $0.22 \pm 0.01$ & $44.58 \pm 3.30$ & $3.93 \pm 0.77$ \\
\hline F9 & -1 & -1 & $200 \pm 9.8$ & $0.23 \pm 0.02$ & $78.60 \pm 0.49$ & $7.89 \pm 0.04$ \\
\hline
\end{tabular}




\section{Date}

Measurement Type

Sample Name

Scattering Angle

Temperature of the holder

T\% before meas.

Viscosity of the dispersion medium

Form Of Distribution

Representation of result

Count rate

Calculation Results

\begin{tabular}{|c|c|c|c|c|}
\hline Peak No. & S.P.Area Ratio & Mean & S. D. & Mode \\
\hline 1 & 1.00 & $2495.8 \mathrm{~nm}$ & $772.7 \mathrm{~nm}$ & $2100.9 \mathrm{~nm}$ \\
\hline 2 & - & $-\mathrm{nm}$ & $-\mathrm{nm}$ & $-\mathrm{nm}$ \\
\hline 3 & - & $-\mathrm{nm}$ & $-\mathrm{nm}$ & $-\mathrm{nm}$ \\
\hline Total & 1.00 & $2495.8 \mathrm{~nm}$ & $772.7 \mathrm{~nm}$ & $2100.9 \mathrm{~nm}$ \\
\hline
\end{tabular}

Histogram Operations

Size (Median)

Mode

$\%$ Cumulative (1)

$\%$ Cumulative (2)

$\%$ Cumulative (3)

$\%$ Cumulative (4)

$\%$ Cumulative (5)

$\%$ Cumulative (6)

$\%$ Cumulative (7)

$\%$ Cumulative (8)

$\%$ Cumulative (9)

$\%$ Cumulative (10)

Cumulant Operations

Z-Average

$\mathrm{PI}$
17 April 2019 18:41:33

Particle Size

Chitosan Nanoparticles-Size

25.0 deg. C

21077

$0.895 \mathrm{mPa} . \mathrm{s}$

[Standard|

Scattering Light Intensity

1963 kCPS

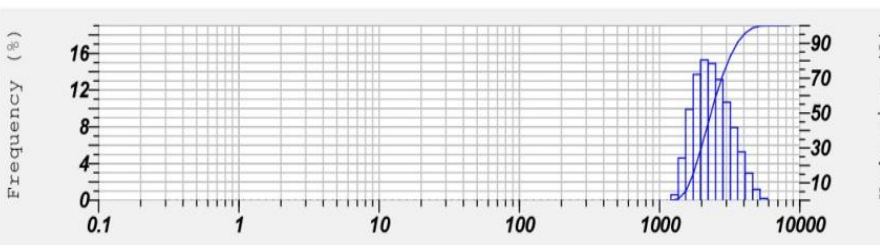

Diameter $(\mathrm{nm})$



Figure-3.5- cumulative particle size of MFA loaded CSNPs

\begin{tabular}{|c|c|c|c|}
\hline \multicolumn{3}{|l|}{ Date } & : 17 April 2019 16:16:09 \\
\hline \multicolumn{3}{|c|}{ Measurement Type } & : Zeta Potential \\
\hline \multicolumn{3}{|c|}{ Sample Name } & : Chitosan Nanoparticles-Zeta \\
\hline \multicolumn{3}{|c|}{ Temperature of the holder } & : $25.1 \mathrm{deg} . \mathrm{C}$ \\
\hline \multicolumn{3}{|c|}{ Viscosity of the dispersion medium } & : $0.893 \mathrm{mPa} . \mathrm{s}$ \\
\hline \multicolumn{3}{|c|}{ Conductivity } & : $0.147 \mathrm{mS} / \mathrm{cm}$ \\
\hline \multicolumn{3}{|c|}{ Electrode Voltage } & $: 3.4 \mathrm{~V}$ \\
\hline \multicolumn{4}{|c|}{ Calculation Results } \\
\hline Peak No. & Zeta Potential & \multicolumn{2}{|c|}{ Electrophoretic Mobility } \\
\hline 1 & $-1.8 \mathrm{mV}$ & \multicolumn{2}{|c|}{$-0.000014 \mathrm{~cm} 2 \mathrm{Vs}$} \\
\hline 2 & $-m V$ & $-\mathrm{cm} 2 \mathrm{Ns}$ & \\
\hline 3 & $-m V$ & \multicolumn{2}{|l|}{$-\mathrm{cm} 2 \mathrm{Ns}$} \\
\hline \multicolumn{3}{|c|}{ Zeta Potential (Mean) } & $:-1.8 \mathrm{mV}$ \\
\hline \multicolumn{3}{|c|}{ Electrophoretic Mobility mean } & : $-0.000014 \mathrm{~cm}^{2} \mathrm{Ns}$ \\
\hline
\end{tabular}

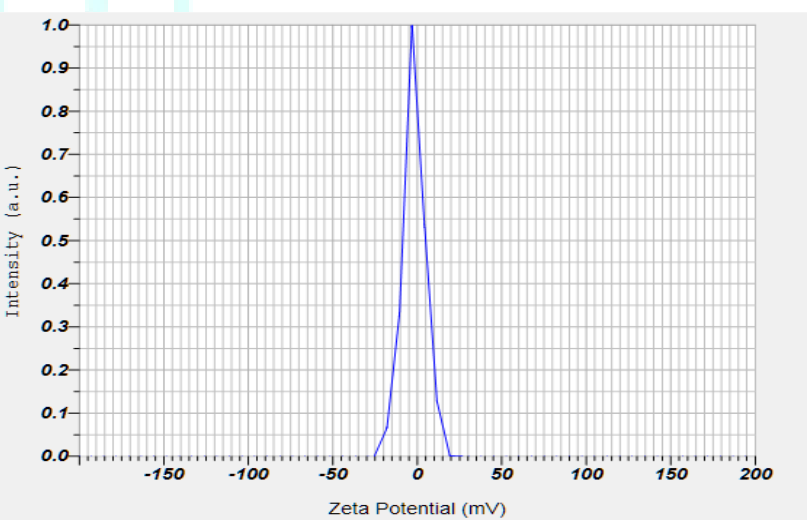

Figure-3.6- Zeta Report of MFA loaded CSNPs

\subsubsection{Morphological studies of MFA loaded chitosan nanoparticles}

The morphological characteristics of Mefenamic loaded CSNPs were observed by SEM. The nanoparticles were found to be a roughly spherical in shape with a smooth surface (Fig. 3.7). The part of an aggregation of the CSNPs was probably because that the hydrogen bonding gradually becomes dominant in the drying process. It also was noticed that these CSNPs have a deeper colour in the core and the surface (white arrows), indicating that these regions have higher electron density distribution. The difference size of CSNPs in DLS and SEM might be attributed to that CSNPs swell in aqueous media. DLS gives a hydrodynamic diameter of nanoparticles, while SEM gives an actual diameter of nanoparticles in the dry state. 

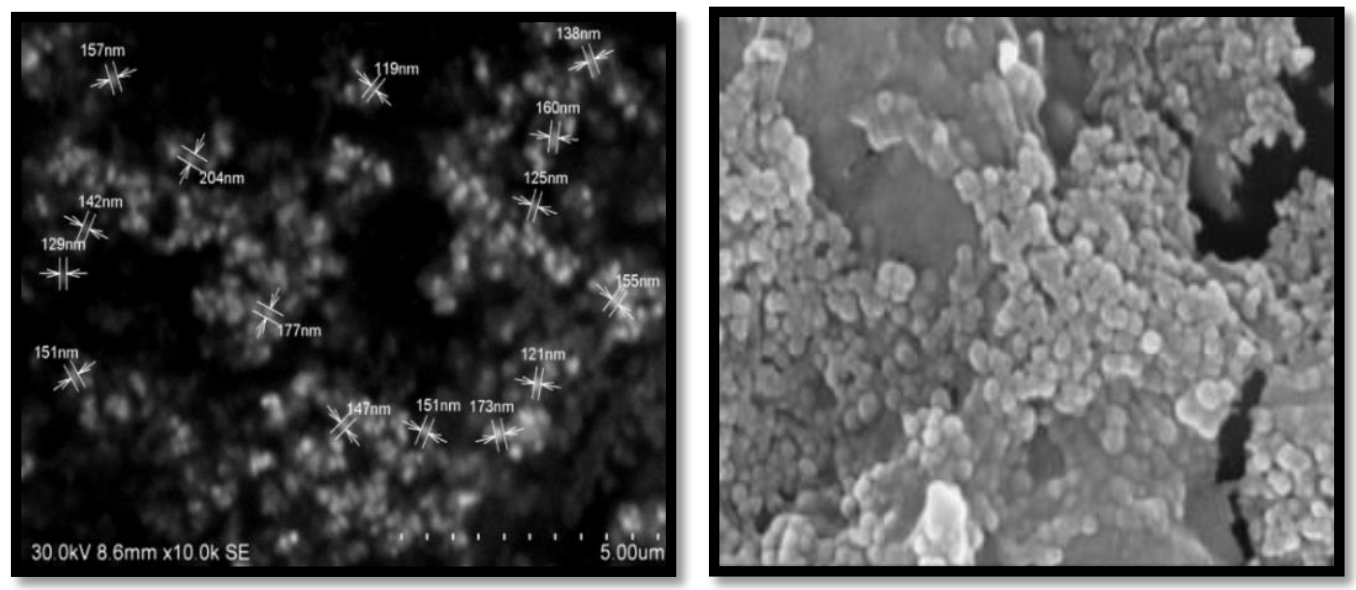

Figure: 3.7- SEM (Scanning Electron micrograph) of Mefenamic acid loaded chitosan nanoparticles

\subsubsection{Drug release profile of MFA loaded chitosan nanoparticles (F1-F9 formulations)}

The release profiles of MFA from the CS-NPs formulations compared to drug solution as a control were illustrated in Figure-3.8.2 and Figure-3.8.3. In control 35.4\% of MFA was released rapidly from the dialysis bag within the first 8 hour. Total drug $99.87 \%$ is released within 14 hours. On the other hand, MFA loaded CSNPs showed a biphasic pattern with an initial burst drug release followed by a sustained release. Regarding CSNPs, MFA was rapidly released within the first 8 $\mathrm{h}$, followed by a slow release from $8 \mathrm{hr}$ up to $26 \mathrm{hr}$. The rapid MFA releasing was mostly due to the nanoparticles surface drugs, which could simply diffuse in the first $8 \mathrm{~h}$. The cumulative percentage release of MFA from the CSNPs in the first $8 \mathrm{~h}$ were about $21 \%, 28 \%, 12 \%, 43 \%, 27 \%, 46 \%, 28 \%$, $33 \%$ and $28 \%$ for F1, F2, F3, F4, F5, F6, F7, F8, F9 and F10. The release profile of $\mathrm{F} 1$ is showing biphasic release having linear release kinetics after $8 \mathrm{hr}$ up to $26 \mathrm{hrs}$.

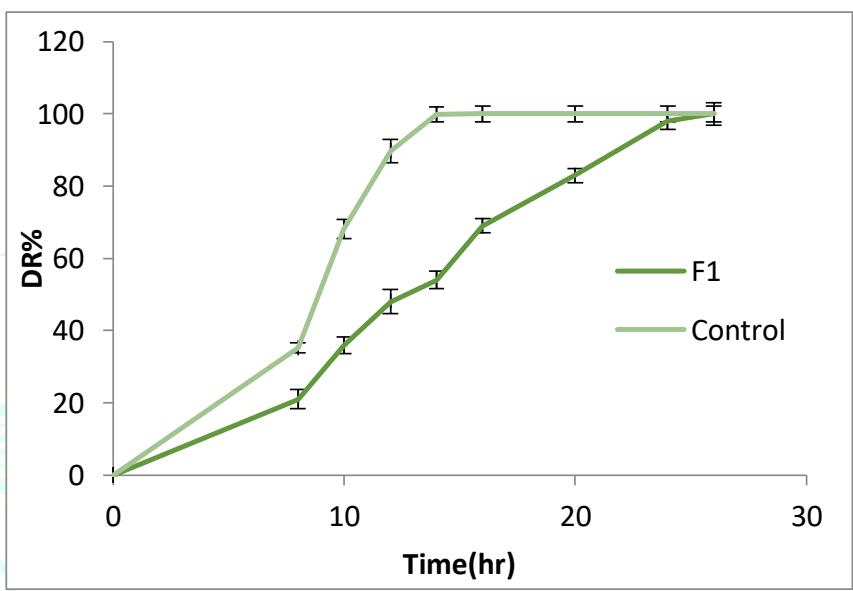

Figure-3.8.1-Drug Release Profile of Control (mefenamic acid) and F1-MFA-CSNPs

Table 3.3- Drug Release profile of MFA loaded Chitosan nanoparticles

\begin{tabular}{|l|l|l|l|l|l|l|l|l|l|l|}
\hline \multirow{2}{*}{$\begin{array}{l}\text { Time } \\
\mathbf{h})\end{array}$} & \multicolumn{9}{|c|}{ In-vitro Release \% } \\
\cline { 2 - 12 } & F1 & F2 & F3 & F4 & F5 & F6 & F7 & F8 & F9 & Control \\
\hline $\mathbf{0}$ & 0 & 0 & 0 & 0 & 0 & 0 & 0 & 0 & 0 & 0 \\
\hline $\mathbf{8}$ & 21 & 28 & 12 & 43 & 27 & 46 & 28 & 33 & 28 & 35.24 \\
\hline $\mathbf{1 0}$ & 36 & 40 & 20 & 55 & 41 & 65 & 40 & 59 & 40 & 68.19 \\
\hline $\mathbf{1 2}$ & 48 & 57 & 31 & 71 & 59 & 79 & 57 & 78 & 57 & 89.77 \\
\hline $\mathbf{1 4}$ & 54 & 62 & 39 & 79 & 65 & 83 & 62 & 83 & 62 & 99.87 \\
\hline $\mathbf{1 6}$ & 69 & 75 & 43 & 89 & 78 & 91 & 75 & 89 & 69 & \\
\hline $\mathbf{2 0}$ & 83 & 79 & 54 & 99.13 & 81 & 100 & 79 & 96 & 73 & \\
\hline $\mathbf{2 4}$ & 98 & 88 & 72 & & 89 & & 88 & 100 & 88 & \\
\hline $\mathbf{2 6}$ & 101 & 99 & 91 & & 98 & & 99 & & 91 & \\
\hline
\end{tabular}






Figure-3.8.2- drug release profile of Control, F1-F5 MFA loaded CSNPs

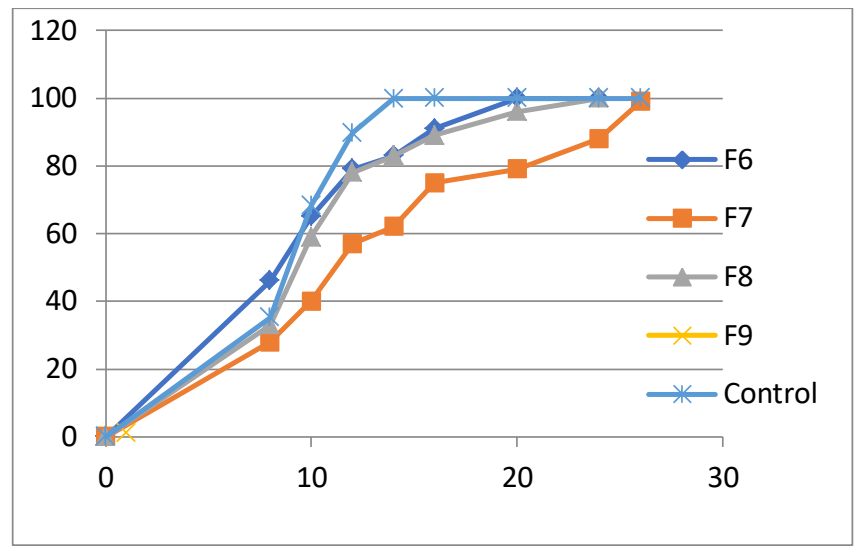

Figure-3.8.3- drug release profile of Control,F6-F9 MFA loaded CSNPs

indicating the hydrogen bonding. The hydrogen bonding in CMCS polymer was at $2893 \mathrm{~cm}^{-1}$ and $2800 \mathrm{~cm}^{-1}$ respectively, and they shifted to 2989 and $2764 \mathrm{~cm}^{-1}$ after MA was encapsulated, The vibration peaks of $1598-1410 \mathrm{~cm}-1$, corresponding to amide I and II bond, had no obvious shift in all formulations. The vibration peak at $1404 \mathrm{~cm}-1$ in CMCS could be assigned to the symmetric stretching.

Figure-3.9 showed the representative FT-IR spectrum CMC NPs In the infrared spectra, an interesting characterization peak was in the range of $2700-3000 \mathrm{~cm}-1$,

3.5 Results of evaluation of MFA loaded CMC nanoparticles

\subsubsection{FTIR results of MFA loaded CMC nanoparticles}

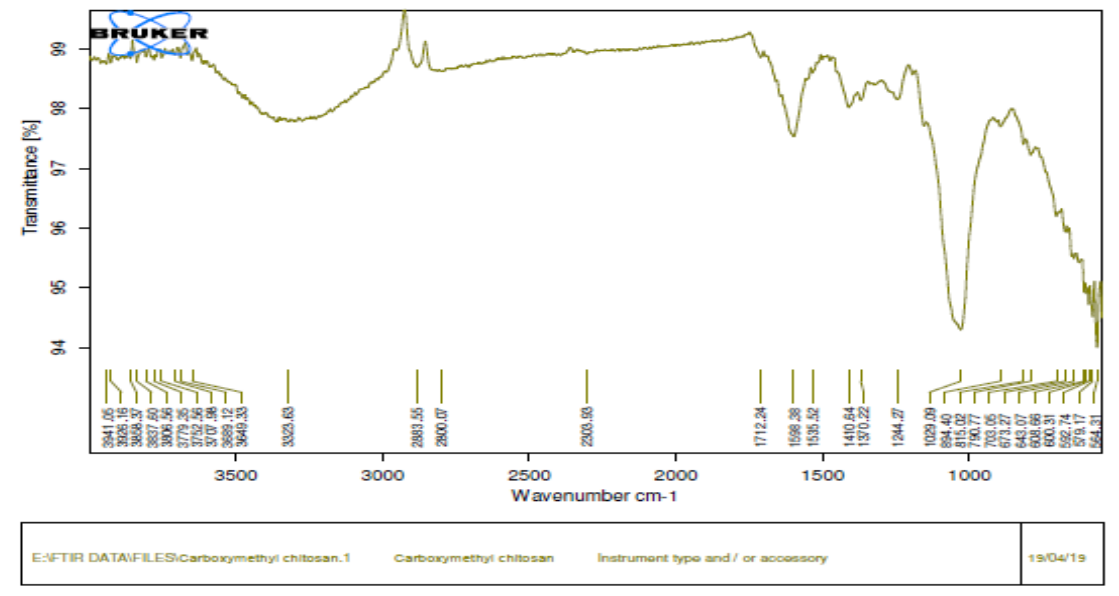

Figurre 3.9.1 FTIR of Carboxy methyl chitosan



E:FTIR DATAFIL ES/Optimized formatlation

Instrument type and / or accessory

Figure-3.9.2 FTIR of MFA loaded CMC nanoparticles 
3.5.2 Effect of concentration and sonication time of CMC on particle size, PDI, EE\% and DL\% of formulations of MFA loaded CMC nanoparticles

The effects of CMC concentration and sonication time on particle size and polydispersity index (PDI) of MFA-loaded CMC nanoparticles were summarized in Table 3.4. The particle size increased linearly from 154 to $201 \mathrm{~nm}$ with the increase of CMC concentration. These trends were in accordance with previously reported results ${ }^{28,29}$.

The results from Table3.4 showed that the interaction effect of Carboxy methyl chitosan concentration and Sonication time on the EE\% and DL\% of MFA loaded CMC-NPs. These results revealed that $\mathrm{EE} \%$ varies from $59.12 \pm 3.30 \%$ to 86.65 \pm 1.16 , F8 having high Carboxy methyl chitosan concentration and longest sonication time showed $86.12 \%$ Entrapment Efficiency due to cross linking of chitosan with drug. DL\% varied from $10.51 \%$ to $19.31 \%$.

This could be attributed to the binding of hydroxyl groups of MFA to positively charged amino groups on Chitosan molecules by electrostatic interaction, these results might be attributed to an increase number of interacting units at higher polymer concentrations and to cross-linker levels that lead to the observed increase in particle size and decrease in entrapment efficiency

For the nanoparticle stability the zeta potential should be between $-25 \mathrm{mV}$ to $+25 \mathrm{mV}$. Zeta potential of chitosan MFA nanoparticle is found to be $-2.8 \mathrm{mV}$ (Figure3.11). The cumulative particle size is $13.9 \mathrm{~nm}$ (Figure-3.10).

Table 3.4- Particle size and PDI of MFA-CMC-NP

\begin{tabular}{|l|l|l|l|l|l|l|}
\hline $\begin{array}{l}\text { Formulation } \\
\text { Code }\end{array}$ & CMC & $\begin{array}{l}\text { Sonication } \\
\text { time }\end{array}$ & Particle size & PDI & EE\% & DL\% \\
\hline F1 & $\mathbf{+ 1}$ & $\mathbf{+ 1}$ & $158.7 \pm 13.4$ & $0.234 \pm 0.0235$ & $59.19 \pm 1.38$ & $12.31 \pm 1.24$ \\
\hline F2 & $\mathbf{0}$ & $\mathbf{+ 1}$ & $170.3 \pm 11.2$ & $0.264 \pm 0.0245$ & $79.18 \pm 2.19$ & $11.21 \pm 1.04$ \\
\hline F3 & $\mathbf{- 1}$ & $\mathbf{+ 1}$ & $168.7 \pm 12.4$ & $0.234 \pm 0.0335$ & $81.52 \pm 1.27$ & $10.51 \pm 1.03$ \\
\hline F4 & $\mathbf{+ 1}$ & $\mathbf{0}$ & $160.3 \pm 11.2$ & $0.264 \pm 0.0205$ & $79.52 \pm 3.39$ & $11.01 \pm 1.64$ \\
\hline F5 & $\mathbf{0}$ & $\mathbf{0}$ & $154.7 \pm 13.4$ & $0.214 \pm 0.0335$ & $82.19 \pm 1.69$ & $15.31 \pm 0.24$ \\
\hline F6 & $\mathbf{- 1}$ & $\mathbf{0}$ & $177.3 \pm 11.2$ & $0.134 \pm 0.0435$ & $80.16 \pm 1.44$ & $12.31 \pm 1.94$ \\
\hline F7 & $\mathbf{+ 1}$ & $\mathbf{- 1}$ & $201.7 \pm 13.4$ & $0.278 \pm 0.0425$ & $78.02 \pm 1.30$ & $19.31 \pm 1.29$ \\
\hline F8 & $\mathbf{0}$ & $\mathbf{- 1}$ & $171.3 \pm 10.2$ & $0.134 \pm 0.0515$ & $86.12 \pm 1.09$ & $18.31 \pm 1.38$ \\
\hline F9 & $\mathbf{- 1}$ & $\mathbf{- 1}$ & $159.2 \pm 12.4$ & $0.264 \pm 0.0235$ & $79.02 \pm 1.29$ & $11.31 \pm 1.44$ \\
\hline
\end{tabular}

$\mathrm{N}=3$ (Mean \pm SD)

\begin{tabular}{|c|c|c|c|c|}
\hline \multirow{2}{*}{\multicolumn{5}{|c|}{ Date }} \\
\hline & & & & : Particle Size \\
\hline \multicolumn{2}{|c|}{$\begin{array}{l}\text { Measurement Type } \\
\text { Sample Name }\end{array}$} & & & \multirow{2}{*}{$\begin{array}{l}\text { CMC Nanoparticles-Size } \\
90\end{array}$} \\
\hline \multicolumn{4}{|c|}{ Scattering Angle } & \\
\hline \multirow{2}{*}{\multicolumn{4}{|c|}{$\begin{array}{l}\text { Temperature of the holder } \\
\text { T\% before meas. }\end{array}$}} & 25.1 deg. C \\
\hline & & & & 20332 \\
\hline \multicolumn{4}{|c|}{ Viscosity of the dispersion medium } & \\
\hline \multicolumn{4}{|c|}{ Form Of Distribution } & $\begin{array}{l}0.893 \mathrm{mPa} . \mathrm{s} \\
\text { |Standard| }\end{array}$ \\
\hline \multicolumn{4}{|c|}{ Representation of result } & Scattering \\
\hline \multirow{2}{*}{\multicolumn{5}{|c|}{$\begin{array}{l}\text { Count rate } \\
\text { Calculation Results }\end{array}$}} \\
\hline & & & & \\
\hline \multirow{2}{*}{\multicolumn{2}{|c|}{\begin{tabular}{|c|c|} 
Peak No. & S.P.Area Ratio \\
1 & 1.00 \\
\end{tabular}}} & \multirow{2}{*}{$\begin{array}{l}\text { Mean } \\
25.9 \mathrm{nn}\end{array}$} & \multirow{2}{*}{$\frac{\text { S. D. }}{42.5 \mathrm{~nm}}$} & \multirow{2}{*}{$\begin{array}{l}\text { Mode } \\
.6 \mathrm{~nm}\end{array}$} \\
\hline & & & & \\
\hline$\frac{2}{3}$ & - & $-n m$ & \multirow{2}{*}{$\begin{array}{c}-\mathrm{nm} \\
-\mathrm{nm} \\
-\mathrm{n}\end{array}$} & $\frac{-n \mathrm{~m}}{-\mathrm{nm}}$ \\
\hline $\begin{array}{c}3 \\
\text { Total }\end{array}$ & $\overline{1.00}$ & $\frac{-\mathrm{nm}}{25.9 \mathrm{~nm}}$ & & $\frac{-\mathrm{nm}}{8.6 \mathrm{~nm}}$ \\
\hline \multicolumn{5}{|c|}{$\begin{array}{l}\text { Total } 1.00 \quad 125.9 \mathrm{~nm} \\
\text { Histogram Operations }\end{array}$} \\
\hline \multicolumn{3}{|c|}{ Size (Median) } & \multirow{2}{*}{\multicolumn{2}{|c|}{$\begin{array}{l}12.5 \mathrm{~nm} \\
8.6 \mathrm{~nm}\end{array}$}} \\
\hline \multicolumn{3}{|l|}{ Mode } & & \\
\hline \multirow{2}{*}{\multicolumn{3}{|c|}{$\begin{array}{l}\% \text { Cumulative (1) } \\
\% \text { Cumulative (2) }\end{array}$}} & \multicolumn{2}{|r|}{$10.0(\%)-5.1(\mathrm{~nm})$} \\
\hline & & & & $50.0(\%)-12.5(\mathrm{~nm})$ \\
\hline$\%$ Cumul & ative (3) & & & $90.0(\%)-55.8(\mathrm{~nm})$ \\
\hline$\%$ Cumul & ative (4) & & & $30.0(\%)-8.1(\mathrm{~nm})$ \\
\hline$\%$ Cumul & tive (5) & & & $40.0(\%)-10.0(\mathrm{~nm})$ \\
\hline$\%$ Cumul & tive (6) & & & $50.0(\%)-12.5(\mathrm{~nm})$ \\
\hline$\%$ Cumul & ative (7) & & & $20.0(\%)-6.5(\mathrm{~nm})$ \\
\hline$\%$ Cumul & ative (8) & & & $70.0(\%)-21.6(\mathrm{~nm})$ \\
\hline$\%$ Cumul & ative (9) & & & $95.0(\%)-91.7(\mathrm{~nm})$ \\
\hline$\%$ Cumul & tive (10) & & & $100.0(\%)-8510.6(\mathrm{~nm})$ \\
\hline Cumula & nt Operati & ns & & \\
\hline Z-Averag & & & & $13.9 n$ \\
\hline & & & & \\
\hline
\end{tabular}



Figure-3.10-Cumulative Particle size graph of MFA-CMC-NP 


\begin{tabular}{|c|c|c|c|}
\hline \multicolumn{3}{|l|}{ Date } & : 17 April 2019 15:58:26 \\
\hline \multicolumn{3}{|c|}{ Measurement Type } & : Zeta Potential \\
\hline \multicolumn{3}{|c|}{ Sample Name } & : CMC Nanoparticles-Zeta \\
\hline \multicolumn{3}{|c|}{ Temperature of the holder } & : 25.0 deg. $C$ \\
\hline \multicolumn{3}{|c|}{ Viscosity of the dispersion medium } & : $0.896 \mathrm{mPa} . \mathrm{s}$ \\
\hline \multicolumn{3}{|c|}{ Conductivity } & $: 0.148 \mathrm{mS} / \mathrm{cm}$ \\
\hline \multicolumn{3}{|c|}{ Electrode Voltage } & $: 3.4 \mathrm{~V}$ \\
\hline \multicolumn{4}{|c|}{ Calculation Results } \\
\hline Peak No. & Zeta Potential & \multicolumn{2}{|c|}{ Electrophoretic Mobility } \\
\hline 1 & $-2.8 \mathrm{mV}$ & \multicolumn{2}{|c|}{$-0.000022 \mathrm{~cm} 2 / \mathrm{Vs}$} \\
\hline 2 & $-m V$ & \multicolumn{2}{|l|}{$-\mathrm{cm} 2 \mathrm{Ns}$} \\
\hline 3 & $-\mathrm{mV}$ & \multicolumn{2}{|l|}{$-\mathrm{cm} 2 \mathrm{Ns}$} \\
\hline \multicolumn{3}{|c|}{ Zeta Potential (Mean) } & $:-2.8 \mathrm{mV}$ \\
\hline \multicolumn{3}{|c|}{ Electrophoretic Mobility mean } & : $-0.000022 \mathrm{~cm}^{2} \mathrm{Ns}$ \\
\hline
\end{tabular}



Figure-3.11-Zeta report of MFA-CMC-NP

\subsubsection{Morphological Results of MFA loaded CMC nanoparticles}

MFA-CMC-NPs, prepared in the optimal condition were observed using SEM (Figure-3.12) All nanoparticleswere spherical or ellipsoidal in shape with a smooth surface and well dispersed without aggregation. Spherical particles with uniform particle size in the nanoscale formed, ranging from 154 to $201 \mathrm{~nm}$. The aggregates, usually having a rod shape, as observed in the SEM photos were probably formed during the drying process. The particle size of nanoparticles obtained after cast drying was in good agreement with that measured in an acidic aqueous system presented.


Figure-3.12-Scanning electron microscopy results of MFA-CMC-NP (Mefenamic acid loaded carboxy methyl chitosan nanoparticles)

\subsubsection{Drug release profile of MFA loaded CMC nanoparticles (F1-F9 formulations)}

The release profiles of MFA from the CMC-NPs formulations compared to drug solution as a control were illustrated in Figure-3.13.1 and Figure-3.13.2. 72.33\% of MFA in control was released rapidly from the dialysis bag within the first 8 hour into solution.Total drug $100.1 \%$ is released within $12 \mathrm{~h}$. On the other hand, MFA loaded CMC-NPs showed a biphasic pattern with an initial burst drug release followed by a sustained release. Regarding CMC-NPs, MFA was rapidly released within the first $8 \mathrm{~h}$, followed by a slow release from $8 \mathrm{hr}$ up to $26 \mathrm{hr}$. The rapid MFA releasing was mostly due to the nanoparticles surface drugs, which could simply diffuse in the first $8 \mathrm{~h}$. The percentage release of MFA from the CMCNPs in the first 8 here about $44.02 \%, 31.72 \%, 34.22 \%$, $37.01 \%, 53 \%, 36.01 \%, 38.33 \%, 61 \%$ and $28 \%$ for $\mathrm{F} 1, \mathrm{~F} 2, \mathrm{~F} 3$, F4,F5,F6,F7,F8,F9and F10,The release profile of F8 is showing biphasic release having linear release kinetics after 8hr upto $26 \mathrm{hr}$ (Figure-3.13.3). 
Table: 3.5- Drug Release Profile of MFA-CMC-NP

\begin{tabular}{|c|c|c|c|c|c|c|c|c|c|c|}
\hline \multirow{2}{*}{$\begin{array}{l}\text { Time } \\
\text { (hr) }\end{array}$} & \multicolumn{10}{|c|}{ In-vitro Release \% } \\
\hline & F1 & F2 & F3 & F4 & F5 & F6 & F7 & F8 & F9 & Control \\
\hline $\mathbf{0}$ & $\mathbf{0}$ & $\mathbf{0}$ & $\mathbf{0}$ & $\mathbf{0}$ & $\mathbf{0}$ & $\mathbf{0}$ & $\mathbf{0}$ & $\mathbf{0}$ & $\mathbf{0}$ & $\mathbf{0}$ \\
\hline 8 & 44.02 & 31.77 & 34.22 & 37.01 & 53 & 36.01 & 38.33 & 61 & 28 & 72.33 \\
\hline 10 & 59.21 & 48.43 & 68.03 & 58.27 & 61.37 & 55.01 & 52.11 & 63 & 40 & 96.32 \\
\hline 12 & 69.43 & 62.02 & 70.11 & 69.43 & 65.04 & 79.12 & 62.01 & 71 & 57 & 100.1 \\
\hline 14 & 82.33 & 75.03 & 74.19 & 82.33 & 71.34 & 83.12 & 72.51 & 72 & 62 & 100.5 \\
\hline 16 & 93.12 & 72.04 & 75.01 & 93.12 & 73.13 & 93.12 & 75 & 81 & 69 & 100.9 \\
\hline 20 & 98.08 & 99.04 & 96.06 & 98.08 & 78.05 & 100 & 81.09 & 94 & 73 & 100.9 \\
\hline 24 & 100 & 100 & 100 & 100 & 92.02 & 100 & 88.43 & 96 & 88 & 100.9 \\
\hline 26 & 100 & 100 & & 100 & 100 & & 99 & 100 & 91 & 100.9 \\
\hline
\end{tabular}

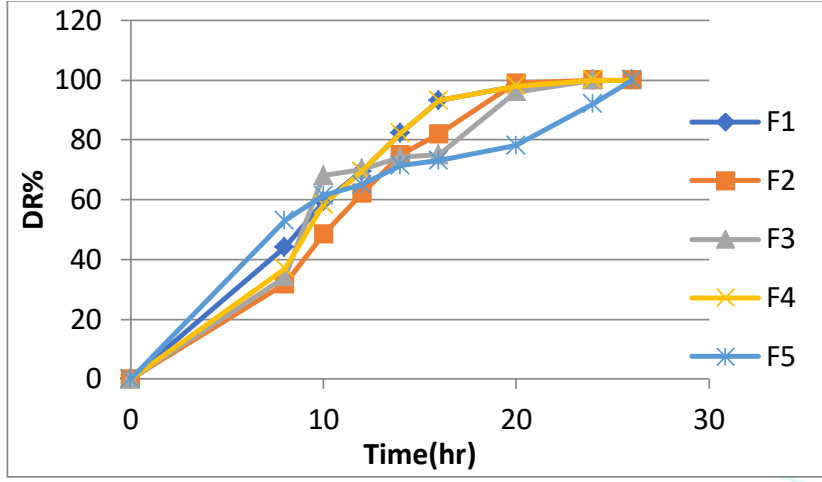

Figure-3.13.1-DR\% of F1 to F5 MFA-CMC- NP

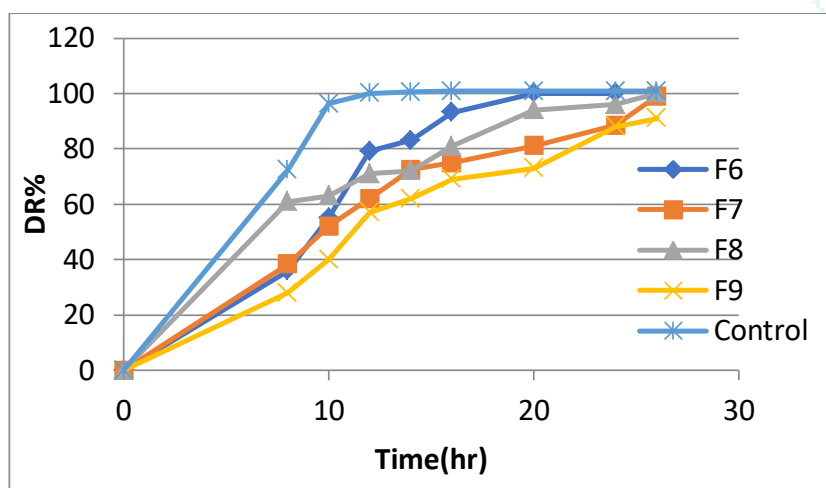

Figure-3.13.2-DR\% of Control, F6 to F9 MFA-CMC-NP



Figure-3.13.3-Drug Release Profile of F8 MFA-CMC-NP and Control
3.5.5 Comparison of Drug release profiles of MFA loaded CMC nanoparticles (Formulation F8), MFA loaded Chitosan nanoparticles (Formulation F1) and control.

The release profiles of MFA from the CMC-NPs formulation F8, Chitosan-NPs formulation F1 compared to drug solution as a control were illustrated in Figure-3.14. MFA was released rapidly from the dialysis bag within the first hour by using the drug solution. On the other hand, MFA loaded CSNPs and CMC-NPs showed a biphasic pattern with an initial burst drug release followed by a sustained release. In both CS-NPs \& CMC-NPs, MFA was rapidly released within the first $8 \mathrm{~h}$, followed by a slow release from $8 \mathrm{hr}$ up to $26 \mathrm{hr}$. The rapid MFA releasing was mostly due to the nanoparticles surface drugs, which could simply diffuse in the first $8 \mathrm{~h}$. In case of CN-MFA-NP formulation 1(F1) is $8,10,12,14,16,20$, 24,26 hours $21 \%, 36,48,54,69,83,98,101 \%$ of drug is releasing. In case of CMC-MFA-NP formulation F8 release profiles are- $61 \%, 63 \%, 71 \%, 72 \%, 81 \%, 94 \%, 96 \%, 100 \%$ at $8,10,12,14,16,20,24,26$ hours respectively. The release profile of F8 of CMC-NPs and F1 of CS-NPs are showing biphasic release having linear release kinetics after $8 \mathrm{hr}$ up to 26 h (Figure-3.14).

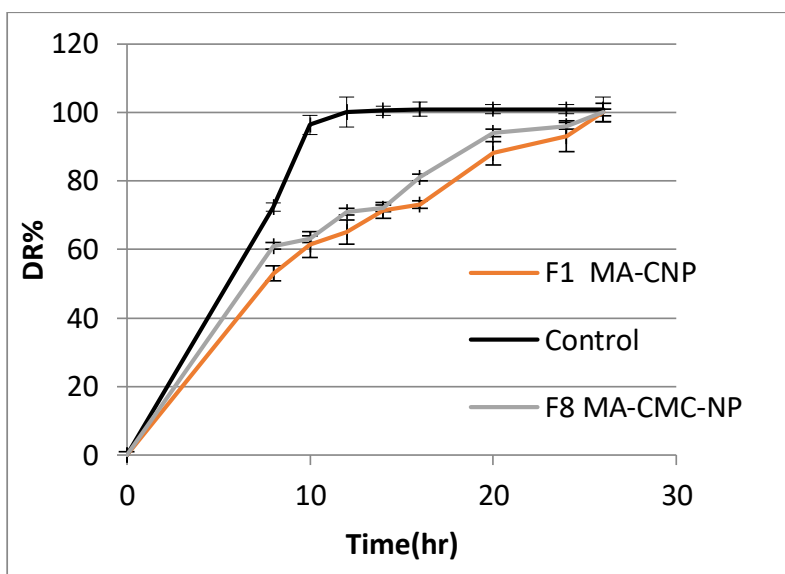

Figure-3.14-Drug Release Profile of Control, F8 of MFACMC-NPs and F1 of MFA-CSNPs 


\subsection{DISCUSSION}

\section{Comparative discussion with previous reviews}

Chitosan is soluble at pKa less than 6, to increase the solubility; chitosan derivatives were synthesized as Tzeneva ${ }^{30}$. The solubility depends on degree of substitution of carboxy methyl groups, which is useful parameter in many applications. The degree of substitution in CMC was between $0.40-0.45$, it was more water soluble as proved by the chen ${ }^{31}$. The degree of substitution was calculated by potentiometric titration in this study as 0.51 (DS of CMC was found to be 0.68 by Vaghani26., 0.6 as per the findings of Mourya ${ }^{32}, 0.89$ as obtained by $\mathrm{Ge}^{33}$, i.e $>0.85$, so their preparative method was said to be perfect method). So the prepared CMC was more water soluble, solubility depends on $\mathrm{NaOH}$ concentration and useful in drug delivery system, similar results were found in case of Mourya ${ }^{32}$, described that $50 \% \mathrm{NaOH}$ was the optimum alkaline solution which favoured the solubility of CMC. Similar results were found by the other researchers ${ }^{34,35}$.

Chitosan-mefenamic acid (40mg) and Carboxy methyl Chitosan- mefenamic acid (40mg) nanoparticles were prepared by solvent evaporation nanoprecipitation method. Chitosan, CMC concentrations, tween 80 and sonication time are taken as variables. The prepared nanoparticle size, Entrapment Efficiency, Poly Dispersity Index, Scanning Electron Microscopy, FTIR, Drug release profile are studied. These Drug release profile obtained for mefenamic acid loaded chitosan nanoparticles (MFA CSNP) were compared with that obtained for mefenamic acid loaded carboxy methyl chitosan nanoparticles (MFA CMC-NP). MFA CSNP entrapment efficiency is ranging from 44.58-82.65\%, Drug loading capacity was 3.95-8.14, particle size ranging from 150-245nm. MFA CMC-NP entrapment efficiency was ranging from $59.19-86.12 \%$, Drug loading capacity is 10.51 19.31, particle size ranging from $154-201 \mathrm{~nm}$. Due to high entrapment efficiency (interaction of $\mathrm{OH}$ groups with the NH2 groups of CMC) the particle size was lesser and drug loading capacity was more than chitosan-MA nanoparticles. Drug release pattern for MFA CSNP and MFA CMC-NP are showing similar release pattern (i.e initial burst release and then sustain release), In case of MFA CSNP formulation 1(F1) is $8,10,12,14,16,20,24,26$ hours $21 \%, 36,48,54,69,83$, $98,101 \%$ of drug was releasing. In case of MFA CMC-NP formulation 7(F7), F8 release profiles were- 38.33, 52.11, $62.01,72.51,75,81.09,88.43,99 \%$ and $61,63,71,72,81,94$, $96,100 \%$ respectively at $8,10,12,14,16,20,24,26$ hours. This drug release profile was depend on the sonication time and the concentration of drug used. MFA CSNP sustain release was observed with high concentration of drug and high sonication time used (F1), whereas MFA CMC-NP sustain release was observed with high concentration of drug with less sonication time used due to the solubility of CMC than chitosan.

\subsection{SUMMARY AND CONCLUSION}

Chitosan is biodegradable polymer. Its application is limited because of its limited solubility at higher range of $\mathrm{pH}$. To overcome this chitosan derivative was prepared by carboxy methylation to obtain carboxymethyl chitosan, was more soluble in wide range of $\mathrm{pH}$. CMC was characterized by FTIR, DS (51\%). CMC was having more applications in sustained and controlled drug delivery systems. Nanoparticles of mefenamic acid loaded chitosan (150-245nm) and CMC (150-201nm) were prepared. Drug release profiles were compared for both nanoparticles. These CMC nanoparticles showed sustain release profile and can release the drug for 26hours.

\subsection{REFERENCES}

1. Sheth P, Sandhu H, Singhal D, Malick W, Shah N and Kislalioglu MS, 'Nanoparticles in the pharmaceutical industry and the use of supercritical fluid technologies for the nanoparticle production', Current drug delivery, 2012; 9(3):269-84

2. Jia, 'Nanoparticle formulation increases oral bioavailability of poorly soluble drugs: Approaches experimental evidences and theory', Current nanosciences, 2005; 1(3): 237-243

3. Singh R and Lillard JW, 'Nanoparticle- based targeted drug delivery', Exp Mol Pathol, 2009; 86(3):215-223

4. Chowdhury A, Kunjiappan S, Pannerselvam T, Somasundaram $B$ and Bhattacharjee $\mathrm{Ch}$, 'Nanotechnology and nanocarrierbased approaches on treatments of degenerative diseases', International nano letters, 2017; 7(2): 91-122

5. Kumar V, Sharma N and Maitra SS, 'In vitro and in vivo toxicity assessment of nanoparticles', International Nano Letters, 2017; 7(4):243-256

6. Monteiller C, Tran L, MacNee W, Faux S, Jones A, Miller B and Donaldson K "The pro-inflammatory effects of low-toxicity low-solubility particles, nanoparticles and fine particles, on epithelial cells in vitro: the role of surface area", Occupational and Environmental Medicine 2007; 64:609-615

7. Kreyling WG, Semmler M, Erbe F, Mayer P, Takenaka S, Schulz $\mathrm{H}$, Oberdorster $\mathrm{G}$ and Ziesenis A, "Translocation of ultrafine insoluble iridium particles from lung epithelium to extrapulmonary organs is size dependant but very low', J Toxicological Environmental Health, 2002; 65(20):1513-30

8. Ray P C, Yu H and Fu P P, "Toxicity and environmental risks of nanomaterials: Challenges and future needs", J Environ Sci Health C Environ Carcinog Ecotoxicol Rev. 2009 Jan; 27(1): 135

9. Kubota N, Tatsumoto N, Sano $\mathrm{T}$ and Toya $\mathrm{K}$, "A simple preparation of half $\mathrm{N}$-acetylated chitosan highly soluble in water and aqueous organic solvents", Carbohydrate research, 2000; 324(4): 268-274

10. Kurita K, "Controlled Functionalization of the Polysaccharide Chitin," Progress in Polymer Science, 2001; 26(9):1921-1971

11. Ahmed TA and Aljaeid BM, 'Preparation, characterization, and potential application of chitosan, chitosan derivatives, and chitosan metal nanoparticles in pharmaceutical drug delivery', Drug design, development and therapy, 2016; 10:483-507

12. Chan JM, Valencia PM, Zhang L, Langer R and Farokhzad OC, 'Polymeric nanoparticles for drug delivery', Methods Mol Biol, 2010; 624:163-75

13. Mohammed M A, Syeda J M, Wasan K M and Wasan E K, "An Overview of Chitosan Nanoparticles and its Application in Non-Parental Drug Delivery", Phrmaceutics,2017; 9(4):53

14. Bellich B, Agostino ID, Semeraro S, Gamini A and Cesaro A, 'The good, the bad and the ugly' of chitosans, Marine drugs, 2016; 14(5):99

15. Yildirimer L, Thanh NTK, Loizidou M, Seifalian AM, 'Toxicology and clinical potential of nanoparticles', Nanotoday, 2011; 6(6):587-607

16. Soares S, Sousa J, Pais A and Votorino C, 'Nanomedicine: principles, properties, and regulatory issues' Frontiers in Chemistry, 2018; 6:360

17. Mourya VK, Inamdar NN.Chitosan-modifications and applications: opportunities galore. React. Funct. Polym. 2008; 68(6):1013-1051

18. Shariatinia Z, "Carboxy Methyl Chitosan: Properties and Biomedical Applications", International Journal Of Biological Macromolecules", 2018; 120 :1406-1419

19. Ali A, Noh N M, Mustafa M A, "Antimicrobial activity of chitosan enriched with lemongrass oil against anthracnose of bell pepper", Food packaging and shelf life, 2015; 3:56-61

20. Muzarelli R, Tanfani F, Emanuelli M, Pace D P, Chiurazzi E, Piani M, "Sulfated N-(carboxymethyl)chitosans: novel blood anticoagulants",Carbohydrate research; 1984; 126(2):225-231

21. Muzarelli R, "Carboxy methylated chitins and chitosans", Carbohydrate Polymers, 1988; 8(1):1-22

22. Muzarelli R, Cucchiara M and Muzarelli C, "N-Carboxymethyl Chitosan in Innovative cosmeceutical products", J. Appl.Cometol, 2002; 20:201-208

23. Younis N, Shaheen M A and Abdullah M H, "Silymarin-loaded Eudragit RS 100 nanoparticles improved the ability of silyamarin to resolve hepatic fibrosis in bile duct ligated rats", Biomedicine \&Pharmacotherapy, 2016; 81:93-103 
24. Reis C P, Neufeld $R$ J, Ribeiro A J and Veiga F, "Nanoencapsulation I. Methods for preparation of drug-loaded polymeric nanoparticles", Nanomedicine,2006; 2:8-21

25. Khan I, Saeed K and Khan I, "Nanoparticles: Properties, applications and toxicities", Arabian journal of chemistry, 2019; 12(7):908-931

26. Vaghani S, Patel M M, Satish C S, Patel K M and Jivani N P, 'Synthesis and characterization of carboxymethyl chitosan hydrogel: Application as site specific delivery for lercanipidine hydrochloride, Bulletin of Material Sciene, 2012; 35(7):11331142

27. Zamani A, Henriksson D and Taherzadeh M J, "A new foaming technique for production of superabsorbents from carboxymethyl chitosan", Carbohydrate Polymers,2010; 80(4):1091-1101

28. Hu F Q, Wu X L, Du Y Z, You J and Yuan H, "Cellular uptake and cytotoxicity of shell crosslinked stearic acid-grafted chitosan oligosaccharide micelles encapsulating doxorubicin" Eur. J. Pharm. Biopharm. 2008; 69(1):117-125

29. Wang, J.; Xu, M.; Cheng, X.; Kong, M.; Liu, Y.; Feng, C.; Chen, X. Positive/Negative Surface Charge of Chitosan Based Nanogels and Its Potential Influence on Oral Insulin Delivery. Carbohydr. Polym. 2016; 136:867-874
30. Tzaneva D, Simitchiev A, etkova N, Nenov V, stoyanova A and Denev P, "Synthesis of Carboxy Methyl Chitosan and its Rheological Behavior in Pharmaceutical and Cosmetic Emulsions", Journal of applied Pharmaceutical Science, 2017; 7(10):070-078

31. Chen L, Du Y, Tian Z and Sun L. Effect of the degree of deacetylationand the substitution of carboxymethyl chitosan on its aggregation behavior. J. Polym. Sci. Polym. Phys. 2005; 43:296-305

32. Mourya V, Inamdar N., Tiwari A. Carboxymethyl chitosan and its applications. Advanced Materials Letters 2010; 1(1):11-33

33. Ge H C and Deng K L, "Preparation of carboxymethyl chitosan in aqueous solution under microwave irradiation", Carbohydrate Research, 2005; 1351-1356

34. Ali Z M, Laghari A J, Ansari A K and Khuhawar M Y, "Synthesis and Characterization of Carboxymethyl Chitosan and its Effect on Turbidity Removal of River Water", Journal of Applied Chemistry,2013; 5 (3):72-79

35. Chen X, Park H. Chemical characteristics of O-carboxymethyl chitosans related to the preparation conditions. Carbohyd. Polym. 2003; 53(4):355-359 